\title{
CONHECIMENTO DE MANIFESTAÇÕES ORAIS DA LEUCEMIA E PROTOCOLO DE ATENDIMENTO ODONTOLÓGICO.
}

\section{KNOWLEDGE OF ORAL MANIFESTATIONS OF THE LEUKEMIA AND PROTOCOL FOR DENTAL CARE.}

\author{
Sueli de Souza Costa* \\ Antonia de Mesquita Silva** \\ Isabela de Avelar Brandão Macedo**
}

\section{RESUMO}

O objetivo deste artigo é destacar a necessidade da leitura correta da série branca do hemograma para o diagnóstico da leucemia, doença que pode levar o paciente ao óbito em pouco tempo e cujas primeiras manifestações ocorrem na cavidade oral. Há maior incidência de leucemias em trabalhadores de determinadas profissões, que estão expostos a agentes físicos e químicos, sendo de fundamental importância o papel do cirurgião-dentista no diagnóstico precoce dessa enfermidade. Destaca ainda a responsabilidade do CD no conhecimento das manifestações orais que ela traz, e apresenta um protocolo de atendimento odontológico ao paciente portador de leucemias, no sentido de minimizar as consequências da terapia das leucemias.

Descritores: Mucosa bucal - patologia • Leucemia • Manifestações bucais • Odontologia do trabalho.

\section{ABST RACT}

The objective of this article is to detach the necessity of the correct reading of the white series of the blood test for the diagnosis of the leukemia, an illness that can take the patient to the death in. Little time and whose first manifestations occur in the oral mucous. There is a higher incidence of leukemia among workers in certain occupations that are exposed to physical and chemical agents, being of fundamental importance the role of dental surgeons in the early diagnosis of this disease. It still detaches the responsibility of the surgeon dentist in the knowledge of the verbal manifestations that it brings, and presents a protocol of oral attendance to the carrying patient of leukemias, in the direction to minimize the consequences of the therapy of the leukemias.

KEY WORDS: Mouth mucosa - pathology • Leukemia • Oral manifestations • Occupational dentistry.

* Mestre em odontologia da Universidade Cruzeiro do Sul (Unicsul); especialista em estomatologia da Universidade Santo Amaro (Unisa) e odontologia do trabalho do Conselho Federal de Odontologia (CFO). E-mail: scsueli@gmail.com

** Especialista em odontologia do trabalho (Slmandic). E-mail: antoniasaudema@gmail.com

*** Pesquisadora do LPPS-Instituto de Tecnologia e Pesquisa de Sergipe, mestranda em saúde e ambiente da Universidade Tiradentes (UNIT) especialista em odontologia do trabalho (Sind. CD Sergipe). E-mail: isavelar@hotmail.com 


\section{INT RODUÇ ÃO}

Leucemia é um grupo de doenças malignas, complexas e diferentes entre si, caracterizadas pela produção excessiva e progressiva de leucócitos, que surgem no sangue em formas imaturas. Afeta cerca de 13 em 100 mil pessoas todos os anos, sendo o tipo linfótico crônico o mais comum, atingindo principalmente idosos (Neville1, 2004). Na leucemia, o crescimento de leucócitos é desordenado e independente, sendo que estes perdem suas funções, com frequência levando o paciente ao óbito.

A etiologia da maioria das leucemias é incerta, mas alguns autores citam infecção viral, exposição à radiação ionizante e outros tipos de radiação eletromagnética, além de exposição química.

Para $\operatorname{Costa}^{2}$ (2005), a prática, o conhecimento e a pesquisa na área da saúde estão engrenados ao processo de produção econômica, sendo que a Revolução Industrial trouxe impacto à saúde do trabalhador, vitimado de acidentes fatais e de intoxicações agudas, principalmente devidas à exposição a agentes químicos, físicos e ambientais. Mas a salubridade no local de trabalho sempre foi utópica (Costa $\left.{ }^{2}, 2005\right)$.

O Instituto Nacional do Câncer em Bethesda, Estados Unidos, em trabalho realizado por Hauptmann et al. ${ }^{3}$ (2009), aponta evidências epidemiológicas de associação entre a exposição ao formaldeído e o risco de leucemia mieloide, em funcionários de funerárias que trabalham com formol, produto usado para embalsamar cadáveres, por longos períodos. O formol também é utilizado para confecção de seda artificial, celulose, tintas e corantes, soluções de ureia, resinas, vidros, espelhos e explosivos. Outras profissões também estariam expostas ao maior desenvolvimento da doença. Para Costa ${ }^{4}$ (2008), o benzeno, integrante do petróleo, é tóxico, altamente cancerígeno e está diretamente associado a doenças como aplasia de medula e leucemias. Vários autores destacam maior risco de desenvolvimento de leucemias para trabalhadores do setor elétrico (Bastuji-Garin et al. ${ }^{5}, 1990$, Flodin et al. ${ }^{6}$, 1986, Milham ${ }^{7}, 1985$, Stern et al. ${ }^{8}, 1986$,
ISSN 1983-5183

Theriault et al. $\left.{ }^{9}, 1994\right)$ e eletromagnético (Milham $^{10}$, 1982).

Autores como Neville' (2004) citam fatores genéticos combinados a fatores ambientais como responsáveis pelo surgimento da leucemia. Anormalidades citogenéticas têm sido demonstradas na maioria das leucemias, sendo que alterações cromossômicas podem inativar o gene supressor de tumor ou ativar os oncogenes, permitindo a proliferação irregular de células hematopoiéticas (McKenna ${ }^{11}$, 2000).

O diagnóstico da leucemia é dado pela identificação de células hematopoiéticas anormais no sangue periférico e medula óssea. Sua caracterização é feita por marcação citoquímica, imunofenotipagem e análise citogenética de anormalidades cromossômicas (Oliveira ${ }^{12}$, 1990). Para Neville ${ }^{1}$ (2004), é necessária a confirmação da imuno-histoquímica de determinadas enzimas características, para identificar e classificar as leucemias mieloides.

As principais formas de leucemia diferem segundo os autores. Alguns, como Neville' (2004), informam serem de quatro tipos: mieloide aguda ou mieloide crônica, linfoide aguda ou linfoide crônica. Outros, como (Shafer et al. ${ }^{13}$, 1987) informam serem três os tipos de leucemia: mieloide, linfoide e monocítica, sendo que estes três tipos podem ainda ser modificados pelo curso da doença (aguda, subaguda ou crônica). Os termos mieloide, monocítica e linfoide determinam o tipo de célula envolvido (origem histogenética).

A leucemia aguda determina sobrevida menor do que seis meses, segundo Shafer et al. ${ }^{13}$ (1987), mas chega a uma taxa de $40 \%$ até cinco anos nos pacientes com menos de 60 anos de idade, em tratamento controlado (Neville', 2004). Já a leucemia mieloide crônica pode apresentar uma taxa de sobrevida de cinco anos de $50 \%$ a $60 \%$ se a doença for diagnosticada e tratada no estágio inicial, e a linfoide crônica pode determinar uma sobrevida de até dez anos (Neville $\left.{ }^{1}, 2004\right)$.

A leucemia linfoide aguda acomete cerca de $80 \%$ de todas as leucemias que atingem crianças e adultos jovens (Ziegler et al. $\left.{ }^{14}, 2005\right)$, sendo mais comum em crianças e tem remissão com tratamento em até $50 \%$ dos casos. No Brasil, de
COSTA SS

SILVA AM

MACEDO IAB

CONHECIMENTO DE MANIFESTAÇÕES

ORAIS DA

LEUCEMIA E

PROTOCOLO DE

ATENDIMENTO

ODONTOLÓGICO.
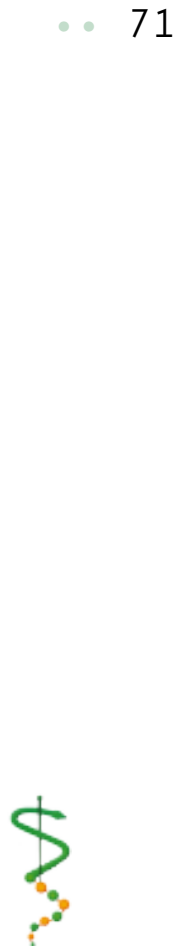

Revista de ODONTOLOGIA DA UNIVERSidade Cidade de São

Paulo

$2011 ; 23(1): 70-$

8, JAN-ABR 
COSTA SS

SI LVA AM

MACEDO IAB

CONHECIMENTO DE MANI FESTAÇÕES

ORAIS DA

LEUCEMIA E

PROTOCOLO DE

ATENDIMENTO

ODONTOLÓGICO.

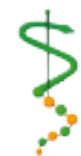

REVISTA DE

ODONTOLOGIA DA UNIVERSIDADE

CIDADE DE SÃO PAULO

$2011 ; 23(1): 70-$

8, JAN-ABR dez a quinze casos de câncer, na faixa etária abaixo de 15 anos, quatro são de leucemia linfoide aguda (Childers et al. ${ }^{15}$, 1993). Mas a sobrevida depende de vários fatores, como origem histogenética envolvida, idade do paciente e tipo de leucemia (Neville 1 , 2004). A aguda é rapidamente progressiva e afeta a maioria das células primitivas, imaturas, que perdem a capacidade de desempenhar as suas funções normais. A leucemia crônica progride lentamente e permite o crescimento de maior número de células já desenvolvidas, que podem exercer algumas de suas funções normais.

$\mathrm{Na}$ infância, a leucemia linfoide aguda ocorre predominantemente, por volta de quatro anos de idade, e é duas vezes mais comum em pacientes caucasianos do que os não caucasianos (Goodman e Gilman ${ }^{16}$, 1996).

\section{I SCUSSÃO}

Para melhor entender o processo de leucemia, é preciso explicar o hemograma. O sangue é composto do plasma e células em suspensão. O plasma é formado por água onde estão proteínas, hormônios, minerais, vitaminas e anticorpos. As células são glóbulos vermelhos, plaquetas e glóbulos brancos que se dividem em neutrófilos, eosinófilos, basófilos, monócitos e linfócitos. Os glóbulos vermelhos perfazem quase $50 \%$ do volume do sangue e se compõem de uma proteína, a hemoglobina, que tem como função a captação de oxigênio nos pulmões, levando-o aos tecidos. As plaquetas têm a função de controlar as hemorragias.

Os glóbulos brancos são compostos de várias células: a) neutrófilos e monócitos (fagócitos); b) linfócitos (principal função é a produção de imunidade), presentes em sua maioria no baço e nos gânglios e também em menor número no sangue periférico. Existem três tipos: os linfócitos $\mathrm{T}$, B e os NK (Natural Killer); c) eosinófilos e basófilos (atuam principalmente nas respostas alérgicas).

A medula óssea é um tecido esponjoso onde ocorre a produção das células sanguíneas, no processo de hematopoese. Um número de células indiferenciadas, denominadas células-tronco hematopoé- ticas, produz o sangue na medula óssea, transformando-se em todas as células do sangue, através do processo de diferenciação (Miller e Gonçalves ${ }^{17}$, 1995). Em seguida, as células diferenciadas atingem a circulação sanguínea, a fim de exercer suas funções. Na leucemia, esse processo não se completa, de forma que células imaturas passam a circular no sangue (Ver Quadros 1 e 2).

\section{Manifestações orais da leucemia}

O primeiro sinal ou sintoma de leucemia ocorre na boca (Weckx et al. ${ }^{18}$, 1990), sendo mais comum nas fases agudas da doença (Shafer et al. ${ }^{13}, 1987$ ), e mais frequentes na leucemia monocítica (Burket). Manifestações clínicas dessa doença podem ocorrer em todos os órgãos e tecidos irrigados e nutridos pela corrente sanguínea.

Várias complicações orais podem ocorrer durante a terapia de remissão e indução para leucemia aguda, e segundo Declerck e Vinckier ${ }^{19}$ (1988), e Segelman e Doku ${ }^{20}$ (1977), são classificadas em primárias (resultam da infiltração de células malignas nas estruturas bucais como infiltração gengival e óssea); secundárias (associadas à trombocitopenia e granulocitopenia como lesões associadas à anemia, tendência a sangramento, suscetibilidade a infecções e úlceras); terciárias (associadas à terapia mielossupressiva e imunossupressiva de citotoxicidade direta ou indireta).

As lesões primárias que ocorrem na gengiva são caracterizadas por aumento da papila interdental e da gengiva marginal. A gengiva fica friável, sangra com facilidade e podem ocorrer infecções secundárias. Podem ocorrer gengivite, hiperplasia gengival, hemorragia, petéquias e ulceração de mucosa no palato, assoaIho oral e língua (Neville1, 2004, Shafer et al. ${ }^{13}, 1987$, Dreizen et al. $\left.{ }^{21}, 1986\right)$. Há anemia e deficiência no processo de cicatrização (hemorragias). Pode haver infecções por fungos como a Candida sp, por bactérias como bacilos Gram-negativos e por vírus como o Herpes simples, devido ao resultado da granulocitopenia.

Quanto à hiperplasia gengival (exceto nos desdentados), na mairia das vezes é generalizada, cobre completamente os 
dentes nos casos mais graves, e aparece necrose do ligamento periodontal e osso alveolar em alguns casos (Shafer et al. ${ }^{13}$, 1987).

Nos pacientes leucêmicos, há pontos de sangramento nos lábios, gengiva, língua, assoalho oral. Neville ${ }^{1}$ (2004) informa que a ulceração de mucosa oral é comum devido à redução da capacidade do hospedeiro em combater a flora microbiana normal, facilitando a infecção de mucosa gengival, resultando em gengivites e em infecções causadas por fungos, ou o surgimento de manifestações do Herpes simples, que tem predileção por mucosa queratinizada (Neville1, 2004, Declerck e Vinckier ${ }^{19}$, 1988, Freitas e Consolaro ${ }^{22}$, 1990). Com o agravamento, há necrose tecidual e o aparecimento de grande quantidade de úlceras. Para pacientes com problemas de sangramento (Neville ${ }^{1}$, 2004), podem ser necessárias transfusões com plaquetas.

Pode haver aumento gengival geral difuso, principalmente nos pacientes com leucemia monocítica, ou ocorrer crescimento gengival proeminente semelhante a tumor (sarcoma granulocítico ou tumor mielóide extramedular), devido à infiltração de células leucêmicas nos tecidos moles da boca (Neville', 2004).

A quimioterapia pode provocar complicações diretamente na mucosa oral, que variam de acordo com a droga e com o estado do paciente. Na imunossupressão severa, as drogas quimioterápicas podem apresentar toxidade medular, e o paciente fica suscetível a estados que podem levar à morbidade e mortalidade (McGuire et al. ${ }^{23}$, 1993). Dependendo de alguns fatores, como condições gerais do paciente e abordagem terapêutica, a mucosa oral cicatriza em média em duas semanas, sem qualquer tratamento específico (Declerck e Vinckier ${ }^{19}, 1988$, Sonis et al. ${ }^{24}, 1985$, Sonis $^{25}, 2004$, Sonis et al. ${ }^{26}, 1978$, Williams e Lee $\left.{ }^{27}, 1991\right)$.

As complicações orais da quimioterapia antineoplásica podem se dar por dois mecanismos: por ação direta da droga sobre os tecidos orais ou estomatotoxidade direta, quando surgem mucosites em função da atrofia epitelial e necrose decorrente (Dreizen et al. ${ }^{21}$, 1986, Williams e
Lee $\left.^{27}, 1991\right)$; e por alterações induzidas em outros tecidos, ou estomatotoxidade indireta.

As reações tóxicas acontecem corriqueiramente na região oral, pois a reprodução celular do epitélio da boca ocorre com frequência similar ao crescimento tumoral. Após o $5^{\circ}$ dia do início da quimioterapia antileucêmica, a boca volta a ser alvo de infecções. A diversidade das drogas utilizadas nos protocolos antineoplásicos leva ao aparecimento de variadas lesões orais, que vão desde a forma sistêmica de candidose (Greenberg et al. ${ }^{28}$, 1982, Ribas e Araújo ${ }^{29}$, 2004) a mucosites.

A mucosite é uma inflamação da mucosa oral, que ocorre como efeito colateral do tratamento quimioterápico realizado para controle da leucemia, principalmente a linfoide aguda; mais comum em crianças (Galvão et al. ${ }^{30}$, 2006, Santos et al. $\left.{ }^{31}, 2003\right)$. Alguns autores recomendam a utilização da terapia de controle estomatológico da mucosite com uso tópico de gluconato de clorexidina e laser de baixa intensidade, que facilitam a eliminação e controle de infecção oral e a cicatrização mais rápida do tecido lesado do que o tempo usual (Cheng et al. ${ }^{32}, 2004$, Sandoval et al. ${ }^{33}$, 2003). Outros sugerem o uso de nistatina e bochechos com clorexidina na prevenção de complicações orais da leucemia (Epstein et al. ${ }^{34}, 1992$ ).

É recomendável a remoção de focos de infecção de origem dentária para se evitar bacteremias (Greenberg et al. ${ }^{28}$, 1982).

\section{PROTOCOLO DE ATENDIMENTO \\ Anamnese completa do paciente, coma avaliação clínica e radiológica;}

Os primeiros sinais de leucemia se manifestam na região oral (são comuns gengivite, hiperplasia gengival, hemorragia, petéquias e ulcerações);

Realizar extrações de dentes não passíveis de restaurações e com severo comprometimento periodontal, restaurações de lesões de cárie ativa e tratamento endodôntico de dentes com comprometimento pulpar;

Estar atento ao hemograma, leucograma e demais exames realizados pelo paciente, a fim de acompanhar quadros de anemia, com atenção especial em proce-
COSTA SS

SILVA AM

MACEDO IAB

CONHECIMENTO DE MANIFESTAÇÕES

ORAIS DA

Leucemia e

PROTOCOLO DE

ATENDIMENTO

odONTOLÓgico.
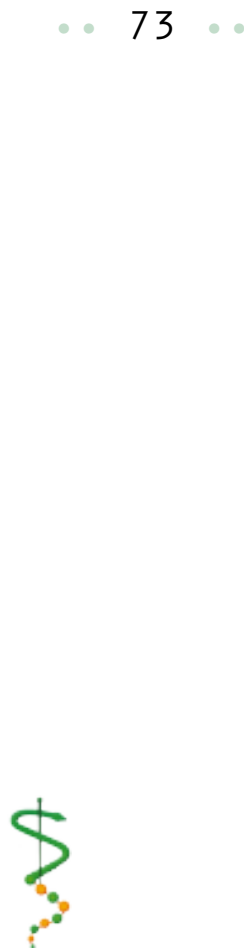

Revista de ODONTOLOGIA DA UNIVERSidade Cidade de São

paulo

$2011 ; 23(1): 70-$

8 , JAN-ABR 
COSTA SS

SILVA AM

MACEDO IAB

CONHECIMENTO DE MANI FESTAÇÕES

ORAIS DA

LEUCEMIA E PROTOCOLO DE

ATENDIMENTO ODONTOLÓGICO.
ISSN 1983-5183

dimentos invasivos, complicados devido às hemorragias, podendo ser necessárias transfusões com plaquetas;

Estar atento para o fato de que a quimioterapia pode provocar complicações diretamente na mucosa oral, que variam de acordo com a droga e com o estado do paciente. $\mathrm{Na}$ imunossupressão severa, as drogas quimioterápicas podem apresentar toxicidade medular, que pode levar o paciente à morbidade e mortalidade;

Durante a terapia antileucêmica, a mucosite é complicação comum, que de pronto deve ser tratada, para evitar debilidade do quadro geral de saúde do paciente pela dificuldade de ingerir alimentos;

Alguns autores recomendam terapia de controle estomatológico da mucosite com uso tópico de gluconato de clorexidina e laser de baixa intensidade. Outros sugerem o uso de nistatina e bochechos com clorexidina na prevenção;

No tratamento da mucosite pode ser necessário o uso de anestésicos locais (lidocaína gel a $2 \%$ ). Se interferir com o grau de nutrição, o paciente pode ser hospitalizado e incluída alimentação total parenteral;

Escovas dentais poderem traumatizar e ferir a boca, mas a higiene oral deve ser incentivada, a fim de evitar reinfecções;

Orientar o paciente para abstenção de tabaco e álcool, e usar frequentemente gelo ou bebidas geladas;

\section{CONCLUSÃO}

O cirurgião-dentista tem papel fundamental no diagnóstico precoce das leucemias, tendo em vista que as primeiras manifestações da doença ocorrem na boca, e os pacientes geralmente o procuram acreditando serem doenças de origem local.

Procedimentos odontológicos, como raspagem periodontal, exodontias e outras cirurgias, são complicados devido às hemorragias, embora seja recomendável a remoção de focos de infecção de origem dentária para se evitar bacteremias.

O uso de escova dental comum pode traumatizar e ferir a boca, mas deve ser incentivada uma ótima higiene oral, a fim de evitar reinfecções. A ulceração ocorre devido ao distúrbio acentuado da distribuição normal dos leucócitos, causando desde uma resposta inflamatória até infecção moderada, que deve de pronto ser eliminada.

Para pacientes com problemas de sangramento, podem ser necessárias transfusões com plaquetas.

Após o $5^{\circ}$ dia do início da quimioterapia antileucêmica, a boca volta a ser alvo de infecções, que devem ser imediatamente tratadas. A diversidade de drogas usadas nos protocolos antineoplásicos levam ao aparecimento de variadas lesões orais, como a forma sistêmica de candidose, língua saburrosa, mucosites, candidose pseudomembranosa e eritematosa, condições estas que devem ser controladas pelo cirurgião-dentista. No caso da mucosite, alguns autores recomendam o uso tópico de gluconato de clorexidina e laser de baixa intensidade, um protocolo que repercute positivamente, facilitando a eliminação e controle de infecção oral e o processo cicatricial mais rápido do tecido lesado.

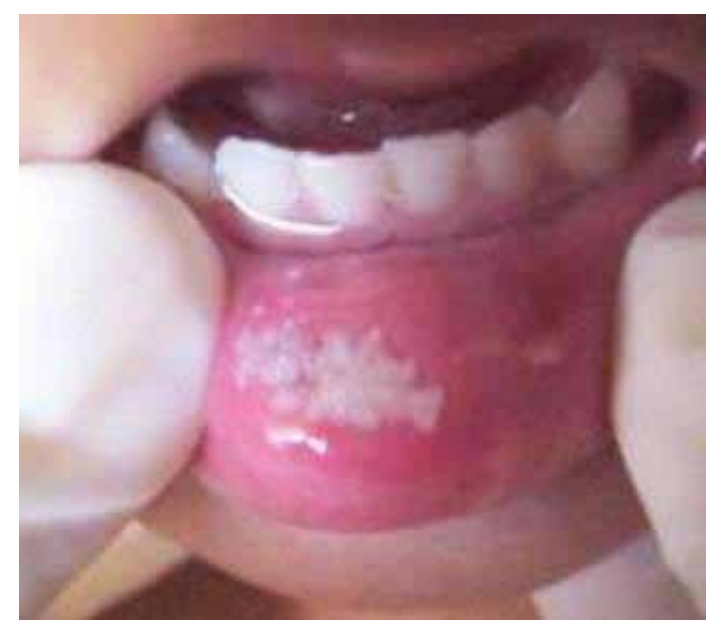

Foto 1: Mucosite em mucosa labial

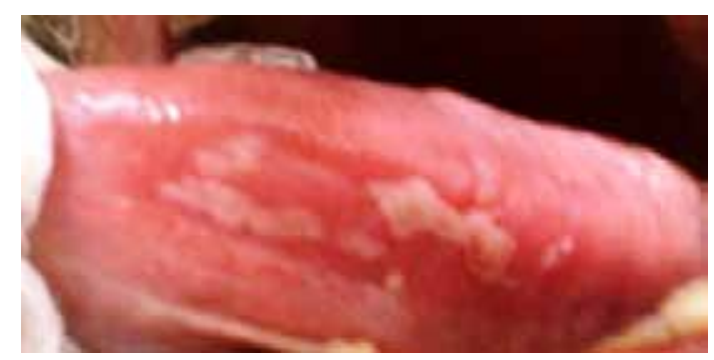

Foto 2: Mucosite em língua 


\section{QUADRO 1}

Hemograma: Interpretação da série branca (Miller, Gonçalves ${ }^{17}, 1995$ ):

Leucócitos: Únicas células nucleadas no sangue, incolores; no adulto: 5.000 a 9.000 células $/ \mathrm{mm}^{3}$ ou mais, no $1^{\circ}$ ano de vida.

A) Seus elementos mieloides são os neutrófilos (entre 45 e $70 \%$ do total, com núcleo multilobulado e grânulos neutros; têm função fagocitária, têm sobrevida de algumas horas), eosinófilos (entre 2 a $4 \%$ do total), basófilos (entre 0 e $1 \%$ do total), monócitos (4 a $8 \%$ do total, dão origem aos macrófagos).

Neutrófilos: São três os mecanismos capazes de alterar a concentração de neutrófilos no sangue: a) Modificação na produção pela medula óssea (aumento da produção, sem perda correspondente, comum em infecções; indica neutrofilia verdadeira); b) Alteração na proporção de células entre os compartimentos (passagem da área marginal para a circulante, por exemplo após exercícios extenuantes; indica falsa neutrofilia); c) Modificação da migração para os tecidos (diminuição da passagem, maior mobilização da medula óssea, desvio do neutrófilo encontrado na área marginal para a circulante, ou devido à administração de glicocorticóides; neutrofilia ineficiente, com aumento da produção, porém aumento do armazenamento intravascular).

Além desses, podem ocorrer neutropenia (diminuição do fornecimento pela medula óssea, aumento da destruição, alteração da distribuição) e alterações na forma dos neutrófilos.

B) Seu principal elemento linfoide é o linfócito (entre 20 a 35\% do total; não possuem grânulos em seu núcleo). São duas classes: B (35\% dos linfócitos; responsável pela imunidade humoral) e T (65\% do total; responsável pela imunidade celular).

\section{QUADRO 2:}

\section{Desvios do leucograma}

\section{Leucócitos:}

a) Leucocitose: Aumento no número total de leucócitos, principalmente linfócitos, neutrófilos e eosinófilos (acima de $9.000 / \mathrm{mm}^{3}$ );

b) Leucopenia: Diminuição no número total de leucócitos (abaixo de 5.000/mm³).

c) Desvio para a Esquerda: Aparecimento de elementos situados à esquerda dos bastonetes; formas imaturas, bastões e metamielócitos. Maior desvio representa número maior de elementos imaturos no sangue periférico. Comum em infecções agudas, no início do processo. Não há desvio nas infecções subagudas, crônicas ou reativadas, mas aumento dos neutrófilos multissegmentados. Indica cronicidade, e pode definir prognóstico, pois a redução do desvio representa evolução favorável do processo.

\section{Neutrófilos:}

a) Neutrofilia: leucócitos acima de $9.000 / \mathrm{mm}^{3}$ e neutrófilos acima de $6.000 / \mathrm{mm}^{3}$. Causas mais comuns: infecções piogênicas e viróticas; complicações supuradas de infecções leucopenizantes, leucemia mielocítica, policitemia, metaplasia mieloide, mielofibrose; neutropenia crônica idiopática, neutrofilia hereditária, adenocorticosteroides; neoplasmas malignos em crescimento rápido; destruição de tecido; período pós-operatório, choque; intoxicações; leucocitoses transitórias.

b) Neutropenia: redução dos neutrófilos (abaixo de 2.500/(mm³) por diminuição da produção (drogas como antibióticos, anticonvulsivantes, diuréticos, AINEs; parada carencial na maturação dos granulócitos; lesões químicas ou físicas, doenças da medula óssea; infecções como mononucleose infecciosa, hepatites, leishmaniose, AIDS); por aumento da destruição (em infecções graves ou protraídas; anticorpos antineutrófilos; doenças autoimunes; iatrogenia); por distribuição alterada (fase inicial das viroses, infecção bacteriana de grande monta, processos alérgicos).

\section{Basófilos:}

a) Basofilia: Causas: doenças do sangue; após esplenectomia; infecções crônicas; após injeção de proteínas estranhas.

\section{Eosinófilos:}

a) Eosinofilia: eosinófilos em quantidade acima de $4 \%$ ou $400 / \mathrm{mm}^{3}$. Causas: doenças
COSTA SS

SILVA AM

MACEDO IAB

ConHecimento de MANIFESTAÇÕES

ORAIS DA

LEUCEMIA E

PROTOCOLO DE

ATENDIMENTO

ODONTOLÓGICO.
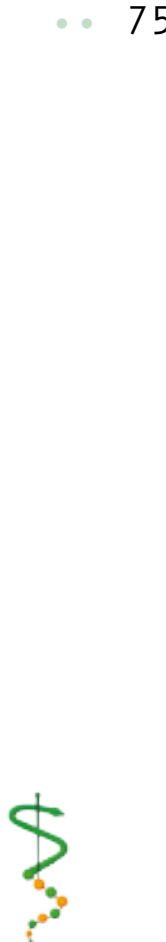

REVISTA DE ODONTOLOGIA DA UNIVERSI DADE Cidade de São PAULO 
do sistema hematopoiético; doenças malignas, especialmente com metástase ou necrose; infecções parasitárias; doenças alérgicas; dermatoses; outros como artrite reumatoide, tóxiCOS, irradiações, granuloma eosinofílico; eosinofilia familiar.

b) Eosinopenia: eosinófilos em quantidade abaixo de $60 / \mathrm{mm}^{3}$ ou total ausência no sangue periférico. Causas: fase inicial de processos infecciosos agudos ou reagudização de processo crônico (eosinófilos em leucograma infeccioso sugere infecção benigna ou em vias de cura); estados tóxicos (coma diabético, uremia, hemólise aguda), choque, queimaduras, anóxia, esforço físico extenuante; administração de ACTH, corticóides, adrenalina; síndrome de Cushing.

\section{Granulócitos:}

a) Agranulocitose: paciente com quadro febril agudo e lesões necróticas em boca e faringe. Há intensa granulocitopenia, linfocitose relativa, ou linfócitos e monócitos reduzidos em números absolutos. Hemáceas e plaquetas não se alteram. Causas: tóxicos industriais, medicamentos, radiações ionizantes, etiologia desconhecida.

\section{Linfócitos:}

a) Linfocitose: presença linfócitos acima de $35 \%$ ou 3.500/ $\mathrm{mm}^{3}$ no adulto ou acima de $45 \%$ em crianças até 3 anos de idade. Causas: leucemia linfocítica e linfomas; infecções agudas com intensa leucocitose e linfocitose, infecções crônicas; convalescença de infecções agudas, fisiológica (criança até 5 anos).

b) Linfocitopenia: só tem valor se for absoluta, menos de $1.200 / \mathrm{mm}^{3}$ e menos de $2.000 /$ $\mathrm{mm}^{3}$ na criança até 3 anos. Indica mau prognóstico, exceto em fase aguda da febre tifoide e gripe. Causas: imunodeficiência; infecções graves, fase inicial de neoplasias, doença de Hodgkin, linfomas, administração de drogas citostáticas.

\section{Monócitos:}

a) Monocitose: quantidade de monócitos acima de $8 \%\left(650 / \mathrm{mm}^{3}\right)$. Causas: leucemia monocítica, linfoma e infecções bacterianas; fase defensiva das infecções agudas (melhora da agranulocitose); infecções por protozoários; doença de Hodgkin, doença de Gaucher; tratamento crônico com doses elevadas de esteroides.

b) Monocitopenia: quantidade de monócitos abaixo de $4 \%$ ou $150 / \mathrm{mm}^{3}$. Causas: fase aguda de processos infecciosos; caquexia, desnutrição.

\section{Quadro Leucêmico}

Cifra de leucócitos aumentada, normal ou francamente leucopênica. Série vermelha entre 2.000 .000 a $3.000 .000 / \mathrm{mm}^{3}$ no início da doença, já com eritroblastos orto ou policromáticos. Quando as células são altamente indiferenciadas, denomina-se o quadro de "leucemia de células-tronco". Leucemia aguda: Contagem de leucócitos abaixo do normal na fase inicial da doença, elevando-se na fase terminal; anemia e trombocitopenia presentes; em consequência, tempo de sangramento e de coagulação podem ser prolongados, e a prova do laço geralmente é positiva. Leucemia mieloide crônica: os leucócitos podem atingir de 200.000 a $500.000 / \mathrm{mm}^{3}$ ou mais, sendo excepcionais as formas subleucêmicas ou aleucêmicas; formas imaturas em todos os graus. Leucemia linfoide crônica: comum $90 \%$ de linfócitos adultos, poucas formas jovens e leucocitose, porém com menos células que na mieloide, raramente ultrapassando $250.000 / \mathrm{mm}^{3}$. Leucemia monocítica: apresenta células pouco diferenciadas.

Reação Leucemóide: Ocorre quando há elevação muito acentuada dos leucócitos (mais de $30.000 / \mathrm{mm}^{3}$ ), a ponto de suscitar confusão com leucemia. Série vermelha sem anormalidades. Pode ocorrer em situações como infecções, doenças malignas, acidose diabética, período hemorrágico ou pós-hemolítico.

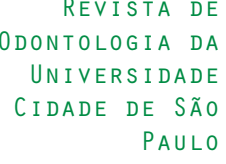

$2011 ; 23(1): 70-$

8, JAN-ABR 
COSTA SS

SILVA AM

MACEDO IAB

CONHECIMENTO DE

MANIFESTAÇÕES

ORAIS DA

LEUCEMIA E

PROTOCOLO DE

ATENDIMENTO

ODONTOLÓGICO.

et al. Mortality from lymphohematopoietic malignancies and brain cancer amon embalmers exposed to formaldehyde. J Natl Cancer Inst 2009 Dec 16;101(24):1696708.

4. Costa D. Prevenção da exposição ao Benzeno no Brasil: análise a partir de uma experiência em São Paulo [Tese]. São Paulo: Faculdade de Medicina da Universidade de São Paulo- USP; 2008.

5. Bastuji-Garin S, Richardson S, Zittoun R. Acute leukaemia in workers exposed to electromagnetic fields. Eur J Cancer 1990 26(11-12):1119-20.

6. Flodin U, Fredriksson M, Persson B, Hardell L, Axelson O. Background radiation, electrical work, and some other exposures associated with acute myeloid leukemia in a case-referent study. Arch Environ Health 1986 Mar-Apr;41(2):77-84.

7. Milham S, Jr. Mortality in workers exposed to electromagnetic fields. Environ Health Perspect 1985 Oct;62(297-300.

8. Stern FB, Waxweiler RA, Beaumont J), Lee ST, Rinsky RA, Zumwalde RD, et al. A case-control study of leukemia at a naval nuclear shipyard. Am J Epidemiol 1986 Jun;123(6):980-92.

9. Theriault G, Goldberg M, Miller AB, Armstrong B, Guenel P, Deadman J, et al. Cancer risks associated with occupational exposure to magnetic fields among electric utility workers in Ontario and Quebec, Canada, and France: 1970-1989. Am J Epidemiol 1994 Mar 15;139(6):550-72.

10. Milham S, Jr. Mortality from leukemia in workers exposed to electrical and magnetic fields. N Engl J Med 1982 Jul 22;307(4):249.

11. McKenna SJ. Leukemia. Oral Surg Oral Med Oral Pathol Oral Radiol Endod 2000 Feb;89(2):137-9.

12. Oliveira H. Hematologia clínica. São Paulo: Atheneu; 1990.

13. Shafer W, Hine M, Levy C. Tratado de patologia bucal. 4 ed. Rio de Janeiro: Guanabara Koogan; 1987.

14. Ziegler DS, Dalla Pozza L, Waters KD, Marshall GM. Advances in childhood leukaemia: successful clinical-trials research leads to individualised therapy. Med J Aust 2005 Jan 17;182(2):78-81.

15. Childers NK, Stinnett EA, Wheeler P, Wright JT, Castleberry RP, Dasanayake AP. Oral complications in children with cancer. Oral Surg Oral Med Oral Pathol 1993 Jan; 75(1):41-7.

16. Goodman L, Gilman A. As bases farmacológicas da terapêutica. Rio de Janeiro: McGraw Hill; 1996.

17. Miller O, Gonçalves R. Laboratório para o clínico. 8 ed. São Paulo: Atheneu; 1995.

18. Weckx LL, Hidal LB, Marcucci G. Oral manifestations of leukemia. Ear Nose Throat J 1990 May;69(5):341-2, 5-6.

19. Declerck D, Vinckier F. Oral complications of leukemia. Quintessence Int 1988 Aug;19(8):575-83.

\section{DOT}

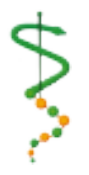

Revista de ODONTOLOGIA DA UNIVERSIDADE Cidade de são Paulo

$2011 ; 23(1): 70-$ 8 , JAN-ABR 
$\operatorname{COSTA} S S$

SILVA AM :

MACEDO IAB

CONHECIMENTO DE MANI FESTAÇÕES

ORAIS DA

LEUCEMIA E

PROTOCOLO DE

ATENDIMENTO

ODONTOLÓGICO.

ISSN $1983-5183$

20. Segelman AE, Doku HC. Treatment of the oral complications of leukemia. J Oral Surg 1977 Jun;35(6):469-77.

21. Dreizen S, McCredie KB, Bodey GP, Keating MJ. Quantitative analysis of the oral complications of antileukemia chemotherapy. Oral Surg Oral Med Oral Pathol 1986 Dec;62(6):650-3.

22. Freitas TC, Consolaro A. Manifestações bucais das leucemias agudas Rev odontol Univ São Paulo 1990 jul.-set.;4(3):261-4.

23. McGuire DB, Altomonte V, Peterson DE, Wingard JR, Jones RJ, Grochow LB. Patterns of mucositis and pain in patients receiving preparative chemotherapy and bone marrow transplantation. Oncol Nurs Forum 1993 Nov-Dec;20(10):1493-502.

24. Sonis S, Fazio R, Fang L. Princípios e prática de medicina oral: medicina de reabilitação. 2 ed. Rio de Janeiro: Guanabara Koogan; 1985.

25. Sonis ST. The pathobiology of mucositis. Nat Rev Cancer 2004 Apr;4(4):277-84.

26. Sonis ST, Sonis AL, Lieberman A. Oral complications in patients receiving treatment for malignancies other than of the head and neck. J Am Dent Assoc 1978 Sep;97(3):468-72.

27. Williams MC, Lee GT. Childhood leukemia and dental considerations. J Clin Pediatr Dent 1991 Spring;15(3):160-4.

28. Greenberg MS, Cohen SG, McKitrick JC, Cassileth PA. The oral flor as a source of septicemia in patients with acute leukemia. Oral Surg Oral Med Oral Pathol 1982 Jan;53(1):32-6.

29. Ribas M, Araújo M. Manifestações estomatológicas em pacientes portadores de leucemia. Rev clín pesq odontol 2004 jul.-ago.;1(1):35-41.

30. Galvão V, Castro CHBC, Consolaro A. Mucosite severa em paciente com leucemia: uma abordagem terapêutica. Rev cir traumatol buco-maxilo-fac 2006 abr.jun.;6(2):35-40.

31. Santos VI, Anbinder AL, Cavalcante ASR. Leucemia no paciente pediátrico: atuação odontológica. Ciênc odontol bras 2003 abr.-jun.;6(2):49-57.

32. Cheng KK, Chang AM, Yuen MP. Prevention of oral mucositis in paediatric patients treated with chemotherapy; a randomised crossover trial comparing two protocols of oral care. Eur J Cancer 2004 May;40(8):1208-16.

33. Sandoval RL, Koga DH, Buloto LS, Suzuki R, Dib LL. Management of chemo- and radiotherapy induced oral mucositis with low-energy laser: initial results of A.C. Camargo Hospital. J Appl Oral Sci 2003 Dec;11(4):337-41.

34. Epstein JB, Vickars L, Spinelli J, Reece D. Efficacy of chlorhexidine and nystatin rinses in prevention of oral complications in leukemia and bone marrow transplantation. Oral Surg Oral Med Oral Pathol 1992 Jun;73(6):682-9.

Recebido em: 4/03/2010

Aceito em:9/08/2010

REVISTA DE

ODONTOLOGIA DA

UNIVERSIDADE

CIDADE DE SÃO

PAULO

$2011 ; 23(1): 70-$

8, JAN-ABR 